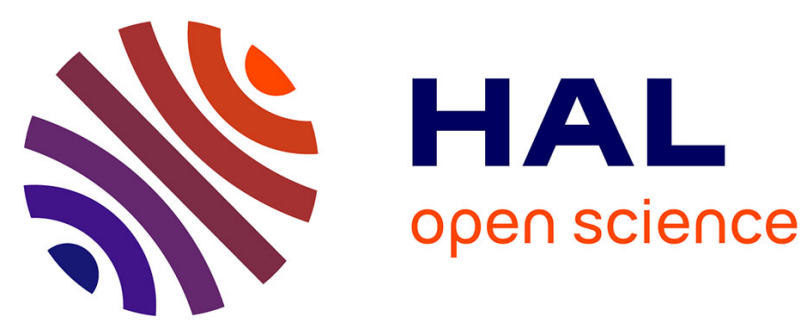

\title{
Utilisation de la culture in vitro d'embryons immatures pour les croisements interspécifiques entre Lactuca sativa L. et L. saligha L. ou L. virosa L.; étude des hybrides obtenus
}

Brigitte Maisonneuve, Yannick Bellec

\section{To cite this version:}

Brigitte Maisonneuve, Yannick Bellec. Utilisation de la culture in vitro d'embryons immatures pour les croisements interspécifiques entre Lactuca sativa L. et L. saligha L. ou L. virosa L.; étude des hybrides obtenus. Agronomie, 1987, 7 (5), pp.313-319. hal-00884996

\section{HAL Id: hal-00884996 https://hal.science/hal-00884996}

Submitted on 1 Jan 1987

HAL is a multi-disciplinary open access archive for the deposit and dissemination of scientific research documents, whether they are published or not. The documents may come from teaching and research institutions in France or abroad, or from public or private research centers.
L'archive ouverte pluridisciplinaire HAL, est destinée au dépôt et à la diffusion de documents scientifiques de niveau recherche, publiés ou non, émanant des établissements d'enseignement et de recherche français ou étrangers, des laboratoires publics ou privés. 


\title{
Utilisation de la culture in vitro d'embryons immatures pour les croisements interspécifiques entre Lactuca sativa L. et L. saligna L. ou $L$. virosa L. ; étude des hybrides obtenus
}

\author{
Brigitte MAISONNEUVE \\ avec la collaboration technique de Yannick BELLEC \\ I.N.R.A., Laboratoire de Génétique et d'Amélioration des Plantes, Centre de Recherches de Versailles, \\ F 78000 Versailles
}

Des hybridations entre especes de la sous-section Lactuca du genre Lactuca ont été réussies par culture in vitro d'embryons mis en culture 7 à 10 jours après la pollinisation sur milieu gélosé avec $20 \mathrm{~g} / 1 \mathrm{de}$ saccharose. Ainsi des hybrides $\mathrm{F} 1$ ( $L$. sativa $\times L$. saligna) et des plantes $\mathrm{RCl}(L$. sativa $\times L$. virosa $) \times L$. sativa ont été obtenus. Les taux de réussite variaient selon l'origine des parents : 17 et 83 plantes hybrides pour 100 capitules pollinisés de chacune des $2 \mathrm{~L}$. saligna étudiées, $0,5,8$ et 11 plantes $\mathrm{RC} 1$ pour 100 capitules pollinisés de chacun des 4 hybrides ( $L$. sativa $\times L$. virosa). Dans des conditions de culture sous serre favorables à la croissance des plantes, quelques descendances F2 ou RC avec $L$. sativa ont été obtenues.

Mots clés additionnels : Hybridation, Lactuca $s p$.

\section{INTRODUCTION}

Des caractères intéressants pour l'amélioration de la laitue cultivée, Lactuca sativa, et en particulier des résistances aux maladies, ont été identifiés chez des espèces sauvages du genre Lactuca. Sur plus de 100 espèces indigènes des régions tempérées de l'hémisphère nord composant ce vaste genre de la famille des Compositae (RYDER \& WHITAKER, 1976), seules des espèces de la section Lactuca semblent avoir été utilisées pour améliorer la laitue cultivée. Cette section, définie par V. FERAKOVA (1976, 1977) d'après des caractères morphologiques, comprend des espèces à $2 \mathrm{n}=18$ chromosomes; parmi celles-ci se trouvent $L$. sativa $L$., $L$. serriola $L$. (appelée à tort $L$. scariola L.), L. saligna L., L. virosa L. et $L$. altaica Fisch et Mey. rassemblées dans la sous-section Lactuca (autrefois considérée comme le groupe Serriola de la section Scariola). Ces 5 espèces forment un groupe de compatibilité et semblent occuper une position isolée par rapport aux autres espèces (THOMPSON et al., 1941).

Des croisements ont donc été réalisés entre $L$. serriola, $L$. saligna et $L$. virosa d'une part et $L$. sativa d'autre part. Les croisements entre $L$. sativa et $L$. serriola sont faciles à réussir et les hybrides $\mathrm{F} 1$ obtenus 
sont en général très fertiles (LINDQviST, 1960). Ainsi, l'introduction chez $L$. sativa des gènes de résistance au mildiou (Bremia lactucae Regel) présents dans cette espèce (BANNEROT, 1980 ; NORWOOD et al., 1980) n'a pas posé de problèmes.

Les croisements entre $L$. sativa et $L$. saligna sont plus difficiles à réussir. Des hybrides n'ont été obtenus qu'en utilisant $L$. saligna comme parent femelle : sur les 139 capitules de $L$. sativa pollinisés par $L$. saligna, LINDQVIST n'a récolté que des graines anormales, ratatinées, incapables de germer (LINDQVIST, 1960). L'introduction chez $L$. sativa de quelques gènes de résistance de $L$. saligna a été signalée dans la littérature : résistance à la chenille du chou (Trichoplusia ni Hubner (WHITAKER et al., 1974) et au virus de la mosaïque du concombre (ProvVIDENTI et al., 1980) de PI 261653 originaire du Portugal, résistance au mildiou (NeTZer et al., 1976) et au Stemphylium (Stemphylium botryosum f. lactucum) (NETZER et al., 1985) de provenances de L. saligna collectées en Israël.

Les croisements entre $L$. sativa et $L$. virosa sont possible dans les 2 sens, mais la production de graines est meilleure en utilisant $L$. sativa comme parent femelle. Il semble cependant très difficile d'obtenir des descendances car les F1 meurent à un stade jeune ou sont très fortement stériles (LINDQVIST, 1960). Aussi le transfert de gènes de $L$. virosa dans $L$. sativa est-il délicat. Pour 2 cas signalés dans la littérature, les auteurs ont réalisé des croisements impliquant 3 espèces : L. sativa, L. serriola, L. virosa. Ainsi la variété Vanguard est issue d'un croisement dont l'un des parents descend d'un hybride trispécifique qui, après traitement à la colchicine, a été pollinisé par $L$. sativa (THOMPSON \& RYDER, 1961). Le transfert à $L$. sativa de la résistance à un aphide (Nasonovia ribis nigri) de $L$. virosa, PIVT 280 , a nécessité l'utilisation de $L$. serriola comme espèce-pont, les hybrides directs (L. sativa $\times$ PIVT 280 ) se nécrosant dans les 30 jours suivant la germination (EENINK et al., 1982). Cepen- dant, quelques descendances partiellement fertiles issues d'un hybride ( $L$. sativa $\times L$. virosa) ont été récemment obtenues par MAXON SMITH (1984). Une nouvelle résistance au mildiou est ainsi en cours de transfert dans L. sativa.

A la station d'Amélioration des Plantes de I'I.N.R.A. de Versailles, dans un programme d'introgression de nouveaux gènes de résistance au mildiou chez la laitue, des croisements entre $L$. sativa et $L$. saligna avaient été tentés sans succès. Un début de croissance des capitules avait cependant été observé dans les jours suivant la pollinisation, mais, à maturité, seules des enveloppes vides étaient récoltées. A partir de lignées $L$. sativa mâle-stériles, nous avons donc tenté en 1984 de refaire ces croisements en utilisant 2 origines de L. saligna comme parents mâles et en prélevant les embryons immatures pour les cultiver in vitro. D'autre part, comme suite aux résultats positifs ainsi obtenus en 1984, et disposant d'hybrides F1 (L. sativa $\times L$. virosa), nous avons appliqué la même technique pour réaliser les rétrocroisements ( $L$. sativa $\times L$. virosa $\times L$. sativa. Cet article présente les résultats des premières expériences de culture d'embryons immatures dans le genre Lactuca et les observations réalisées sur les plantes hybrides ainsi produites.

\section{MATÉRIEL ET MÉTHODES}

\section{A. Matériel végétal}

Le matériel végétal est présenté dans le tableau 1.

Deux origines de L. saligna, fournies par I. CRUTE sous les numéros 16 et 17 et correspondant à des lots de la collection de l'IVT (Wageningen, Pays-Bas), ont été utilisées pour polliniser 2 lignées mâle-stériles de L. sativa: la lignée A 6614 de MAXON SMITH possédant le gène Ms7 (RYDER, 1971) et la lignée I.N.R.A.

TABLEAU 1

Matériel végétal utilisé en croisements.

Plants studied for crosses.

\begin{tabular}{|c|c|c|c|c|}
\hline Espèce & Matériel végétal & $\begin{array}{l}\text { Utilisation } \\
\text { en croisement }\end{array}$ & Origine & Caractéristiques \\
\hline L. saligna & $\begin{array}{ll}\text { CR } 17 \\
\text { CR } 16\end{array}$ & $\sigma^{*}$ & $\begin{array}{l}\text { I. CRUTE (NVRS, Wellesbourne, GB) } \\
\text { I. CRUTE }\end{array}$ & $\begin{array}{l}\text { synonyme de IVT 1346, originaire } \\
\text { d'Israël }\end{array}$ \\
\hline $\begin{array}{c}\mathrm{F} 1 \text { (L. sativa } \times \\
\text { L. virosa) }\end{array}$ & $\begin{array}{l}\text { F1 }(\text { PXC } \times \text { IVT 1398) } \\
\text { F1 }(\text { PXD } \times \text { LS 241) } \\
\text { F1 }(\text { PXD } \times \text { LS 231) } \\
\text { F1 }(\text { PXD } \times=\text { LS 238) }\end{array}$ & $\begin{array}{l}q \\
q \\
q \\
q\end{array}$ & $\begin{array}{l}\text { IVT 1398, IVT (Wageningen, NL) } \\
\text { LS } 241 \text {, I.N.R.A. (Récolte dans la Marne, F) } \\
\text { LS } 231 \text {, I.N.R.A. (Récolte à l'Est du Bassin } \\
\text { Parisien, F) } \\
\text { LS } 238 \text {, I.N.R.A. (Récolte en Seine-et- } \\
\text { Marne, F) } \\
\text { PXC et PXD, lignées I.N.R.A. }\end{array}$ & Type Girelle, mâle stérile \\
\hline L. sativa & $\begin{array}{l}\text { A } 6614 \\
\text { VHD } \\
\text { Ambiance, Columbus, } \\
\text { Girelle, Mélina, Ravel } \\
\text { Capitan } \\
\text { Feuille de Chêne blonde }\end{array}$ & $\begin{array}{l}q \\
q \\
0 \\
o \\
0\end{array}$ & $\begin{array}{l}\text { J. MAXoN SMiTH (GCRI, Littlehampton, } \\
\text { GB) } \\
\text { I.N.R.A. } \\
\text { Variétés commerciales } \\
\text { Variété commerciale } \\
\text { Variété commerciale }\end{array}$ & $\begin{array}{l}\text { Type laitue beurre, mâle stérile } \\
\text { (Ms } 7 / \text { ms } 7 \text { ) } \\
\text { Type laitue beurre, mâle stérile } \\
\text { Type laitue beurre d'abri } \\
\text { Type laitue beurre de plein champ } \\
\text { Type laitue à couper }\end{array}$ \\
\hline
\end{tabular}


VHD à stérilité mâle bigénique récessive issue de 6056 ms de RYDER (RYDER, 1963).

Quatre hybrides interspécifiques ( $L$. sativa $\times L$. virosa) réalisés au laboratoire en 1982 et 1983 ont été pollinisés par quelques variétés commerciales de laitue à raison de 3 à 6 plantes par hybride.

\section{B. Méthode d'hybridation}

Les croisements ont été réalisés sous abri durant l'été par simple frottement des capitules des plantes femelles par des capitules des plantes mâles. Les plantes femelles étant mâle-stériles géniques (A 6614, VHD) ou ne produisant pas de graines en fécondation libre (F1 (L. sativa $\times$ L. virosa)) aucune castration n'a été effectuée. Au total, 131 capitules ont été pollinisés entre le 24 août et le 6 septembre 1984 par L. saligna et 1287 capitules de F1 (L. sativa $\times L$. virosa) ont été pollinisés en juillet 1985 par $L$. sativa.

\section{Culture des embryons in vitro}

Les capitules prélevés ont été désinfectés dans l'hypochlorite de calcium $(24 \mathrm{~g} / \mathrm{l})$ puis disséqués en conditions aseptiques sous une loupe binoculaire. Dans la première expérience, L. sativa $\times L$. saligna, les prélèvements ont été effectués de 3 à 21 jours après la pollinisation et 4 milieux de culture ont été testés, selon les conseils de C. DORÉ (tabl. 2). Différents types d'explants ont été mis en culture sur ces milieux : ovaires, ovules, embryons dégagés des téguments. Dans la deuxième expérience, $(L$. sativa $\times L$. virosa) $\times$ L. sativa, les capitules ont été prélevés 7 à 10 jours après pollinisation et seuls les embryons présentant des cotylédons bien développés ont été mis en culture sur le milieu T0. Dans tous les cas, les embryons se développant ont été repiqués sur T0 pour favoriser l'enracinement. Les cultures ont été effectuées en chambre climatisée : $16 \mathrm{~h}$ avec 2000 lux, $23^{\circ} \mathrm{C}$ le jour, $18^{\circ} \mathrm{C}$ la nuit. Parfois les plantes formées ont été multipliées végétativement sur le milieu T0.

\section{Culture des plantes hybrides}

Les plantes obtenues in vitro sont repiquées dans un mélange tourbe-sable $(3: 2)$ désinfecté à la vapeur et cultivées en chambre climatisée $\left(12^{\circ} \mathrm{C}\right.$ la nuit $/ 16^{\circ} \mathrm{C}$ le jour, $16 \mathrm{~h}$ de jour). Le repiquage a été effectué entre octobre et décembre dans la première expérience et en août dans la seconde expérience. Puis les plantes ont été transférées en serre soit en pots avec différents substrats, soit en pleine terre en 1984, en pots de 2 litres avec un mélange tourbe-argile expansée en 1985. Certaines plantes ( $L$. sativa $\times L$. saligna) et toutes les plantes [( L. sativa $\times L$. virosa $) \times L$. sativa $)]$ ont reçu un éclairage d'appoint de $16 \mathrm{~h}$ par jour.

Les graines issues d'autofécondations ont été récoltées par battage des plantes. De plus, des capitules de quelques plantes $\mathrm{F} 1$ ( $L$. sativa $\times L$. saligna) ont été rétrocroisés, après castration manuelle, par $L$. sativa. D'autre part, 3 plantes $F 1$ ( $L$. sativa $\times L$. saligna) ont été traitées à la colchicine par application, sur les bourgeons axillaires des jeunes plantes, de disques de gélose contenant 5 p.p.m. de colchicine.

TABLEAU 2

Composition des milieux utilisés pour la culture des embryons immatures.

Composition of media used for immature embryo culture.

\begin{tabular}{|c|c|c|c|c|}
\hline & M8 & N2 & Gilieux & B5 \\
\hline Macroéléments & MONNIER, 1973 & Nitsch et NitsCH, 1969 & MURASHIGE et SKOOG, 1962 & GAMBORG et al., 1968 \\
\hline Microéléments & MONNIER, 1973 & BOURGiN et Nitsch, 1967 & HELLER, 1953 & GamBorG et al., 1968 \\
\hline Vitamines & $\mathrm{Bl}$ et $\mathrm{B} 6(1 \mathrm{mg} / \mathrm{l})$ & B1 et B6 $(0,1 \mathrm{mg} / \mathrm{l})$ & MOREL et WeTMORE, 1951 & GAMBORG et al., 1968 \\
\hline Saccharose & $80 \mathrm{~g} / 1$ & $100 \mathrm{~g} / \mathrm{l}$ & $20 \mathrm{~g} / \mathrm{l}$ & $20 \mathrm{~g} / 1$ \\
\hline Agar-agar & $7 \mathrm{~g} / \mathrm{l}$ & $7 \mathrm{~g} / \mathrm{l}$ & $8 \mathrm{~g} / 1$ & $6 \mathrm{~g} / 1$ \\
\hline Divers & $\begin{array}{l}\text { Hydrolysat de caséine } \\
400 \mathrm{mg} / \mathrm{l}\end{array}$ & Glutamine, $400 \mathrm{mg} / 1$ & & \\
\hline
\end{tabular}

\section{RÉSULTATS}

\section{A. Conditions de culture in vitro des embryons}

La première expérience, bien qu'effectuée sur de faibles effectifs, a permis de définir des conditions favorables au développement in vitro d'embryons hybrides interspécifiques.

Ainsi, nous avons obtenu des plantes sur chacun des milieux gélosés testés mais à des taux différents ; plus de la moitié des explants mis en culture sur T0 et B5 se sont développés contre moins de un quart sur M8 et N2. D'après ces résultats les milieux T0 et B5 ont été retenus comme plus favorables au développement des embryons immatures que les milieux M8 et N2.

Des plantes hybrides ont été obtenues après prélèvement des capitules entre le $4^{\mathrm{e}}$ et le $21^{\mathrm{e}}$ jour après la pollinisation. Le tableau 3 montre une variation dans le taux de développement des embryons par capitule prélevé. Les meilleurs taux étaient obtenus lorsque les embryons étaient mis en culture dans la semaine précédant le stade de maturité de graines de $L$. sativa autofécondées, avec en moyenne une plante hybride par capitule pollinisé. Précisons que dans les capitules prélevés tardivement aucune graine hybride mature n'a été récoltée alors que des capitules pollinisés par 
TABLEAU 3

Développement des embryons FI (L. sativa $\times$ L. saligna) et témoins

$F I$ (L. sativa $\times$ L. sativa) mis en culture in vitro 3 à 21 jours après la pollinisation.

Development of F1 (L. sativa $\times$ L. saligna) and standard F1

(L. sativa $\times$ L. sativa) embryos cultured in vitro 3 to 21 days after pollipollination.

\begin{tabular}{|c|c|c|c|c|c|}
\hline \multirow{4}{*}{$\begin{array}{l}\text { Stade de prélèvement } \\
\text { des capitules } \\
\text { en nombre de jours } \\
\text { après la pollinisation }\end{array}$} & \multirow{2}{*}{\multicolumn{5}{|c|}{$\frac{\text { Nombre d'embryons se développant en plantes hybrides }}{\text { Nombre de capitules prélevés }}$}} \\
\hline & & & & & \\
\hline & \multicolumn{4}{|c|}{ L. sativa $\times$ L. saligna } & Témoins \\
\hline & A $6614 \times$ CR 16 & A $6614 \times$ CR 17 & $\mathrm{VHD} \times \mathrm{CR} 17$ & Total & A $6614 \times$ Columbus \\
\hline \multirow{2}{*}{3 à $5 \mathrm{j}$. } & 0 & 3 & \multirow{2}{*}{-} & 3 & 10 \\
\hline & $\overline{5}$ & 3 & & $\overline{8}$ & $\overline{3}$ \\
\hline \multirow[t]{2}{*}{6 à $7 \mathrm{j}}$. & 0 & $\underline{15}$ & 6 & 21 & 13 \\
\hline & $\overline{6}$ & $\overline{17}$ & $\overline{4}$ & $\overline{27}$ & $\overline{3}$ \\
\hline \multirow{2}{*}{8 à $9 \mathrm{j}}$. & $\underline{2}$ & 1 & $\underline{11}$ & 14 & 5 \\
\hline & 4 & $\overline{6}$ & $\overline{3}$ & $\overline{13}$ & $\overline{2}$ \\
\hline \multirow{2}{*}{10 à $11 \mathrm{j}$. } & 3 & 11 & 4 & $\underline{18}$ & 0 \\
\hline & 6 & 9 & 3 & $\overline{18}$ & $\overline{1}$ \\
\hline \multirow[t]{2}{*}{12 à $13 \mathrm{j}}$. & $\underline{0}$ & 7 & \multirow[t]{2}{*}{ - } & 7 & \multirow[t]{2}{*}{-} \\
\hline & 5 & $\overline{4}$ & & $\overline{9}$ & \\
\hline \multirow[t]{2}{*}{14 à $15 \mathrm{j}$. } & 1 & - & 5 & 6 & \multirow{2}{*}{ graines matures } \\
\hline & 1 & & $\overline{4}$ & 5 & \\
\hline \multirow{2}{*}{16 à $21 \mathrm{j}}$. & $\underline{2}$ & 19 & $\underline{0}$ & 21 & \multirow{2}{*}{ graines matures } \\
\hline & $\overline{20}$ & 30 & $\overline{1}$ & $\overline{51}$ & \\
\hline
\end{tabular}

L. sativa, variété Columbus, contenaient des graines matures $14 \mathrm{j}$. après pollinisation. Mais dès le $11^{\mathrm{e}} \mathrm{j}$. après la pollinisation, nous avons observé des embryons expulsés des téguments de la graine. Les embryons atrophiés ou sans cotylédons différenciés ne se sont pas développés, quels que soient la date de prélèvement et le milieu de culture utilisé.

\section{B. Production de plantes hybrides}

Dans la première expérience, les résultats, tous milieux et tous stades de prélèvements confondus, montrent un meilleur développement des hybrides (L. sativa $\times$ CR 17 ) que des hybrides ( $L$. sativa $\times$ CR 16) (tabl. 4) ; L. sativa lignée VHD semble donner un résultat un peu supérieur à la lignée A 6614. Le plus souvent 1 à 2 embryons se sont développés par capitule, mais parfois 3 à 5 embryons d'un capitule ont produit des plantes hybrides. Par une multiplication végétative in vitro des plantules formées, nous avons obtenu un assez grand nombre de plantes hybrides : 17 plantes ( $L$. sativa $\times$ CR 16) et 166 plantes (L. sativa $\times$ CR 17 ) repiquées en terre (tabl. 4) après 12 à 130 jours de culture in vitro.

TABLEAU 4

Production de plantes hybrides FI (L. sativa $\times$ L. saligna) après mise en culture in vitro d'embryons immatures comparaison à des témoins $F I$ (L. sativa $\times$ L. sativa).

Production of $F I$ (L. sativa $\times$ L. saligna) plants from immature embryos cultured in vitro : comparison with standard $F 1$ (L. sativa $\times$ L. sativa).

\begin{tabular}{|c|c|c|c|c|c|}
\hline $\begin{array}{c}\text { Génotype femelle } \\
\text { L. sativa } \\
\text { mâle stérile }\end{array}$ & Génotype mâle & $\begin{array}{l}\text { Nombre de capitules } \\
\text { pollinisés } \\
(=\mathrm{cp})\end{array}$ & $\begin{array}{l}\text { Nombre de capitules } \\
\text { donnant au moins une } \\
\text { plante hybride } \\
(\% 0 \mathrm{cp})\end{array}$ & $\begin{array}{l}\text { Nombre d'embryons } \\
\text { se développant en } \\
\text { plante hybride } \\
(\% \mathrm{cp})\end{array}$ & $\begin{array}{l}\text { Nombre de plantes } \\
\text { hybrides repiquées } \\
\text { en terre après } \\
\text { clonage in vitro }\end{array}$ \\
\hline A 6614 & $\begin{array}{l}\text { L. saligna } \\
\text { CR } 16\end{array}$ & 47 & $\begin{array}{c}6 \\
(13)\end{array}$ & $\begin{array}{c}8 \\
(17)\end{array}$ & 17 \\
\hline A 6614 & $\begin{array}{l}\text { L. saligna } \\
\text { CR } 17\end{array}$ & 69 & $\begin{array}{c}35 \\
(52)\end{array}$ & $\begin{array}{l}57 \\
(83)\end{array}$ & 128 \\
\hline VHD & $\begin{array}{l}\text { L. saligna } \\
\text { CR } 17\end{array}$ & 15 & $\begin{array}{c}10 \\
(67)\end{array}$ & $\begin{array}{c}26 \\
(173)\end{array}$ & 38 \\
\hline A 6614 & $\begin{array}{l}L . \text { sativa } \\
\text { Columbus }\end{array}$ & $9 *$ & $\begin{array}{c}8 \\
(89)\end{array}$ & $\begin{array}{c}28 \\
(311)\end{array}$ & - \\
\hline
\end{tabular}

\footnotetext{
* Non compris 6 capitules prélevés 14 ou 18 jours après la pollinisation et contenant des graines matures.
} 
TABLEAU 5

Production de plantes $R C l \Omega$. sativa $\times \mathbf{L}$. virosa) $\times$ L. sativa par culture in vitro d'embryons immatures prélevés 7 à $10 \mathrm{j}$. après la pollinisation.

Production of $R C I$ (L. sativa $\times$ L. virosa) $\times$ L. sativa

from immature embryos cultured in vitro 7 to 10 days after pollination.

\begin{tabular}{|c|c|c|c|c|}
\hline $\begin{array}{c}\text { Génotype femelle } \\
\text { F1 }(L . \text { sativa } \times L \text {. virosa) }\end{array}$ & $\begin{array}{c}\text { Nombre de capitules } \\
\text { pollinisés par } \\
L . \text { sativa }(=\mathrm{cp})\end{array}$ & $\begin{array}{l}\text { Nombre d'embryons } \\
\text { mis en culture } \\
\text { in vitro }\end{array}$ & $\begin{array}{c}\text { Nombre d'embryons } \\
\text { se développant en plantes } \\
(\% \mathrm{cp})\end{array}$ & $\begin{array}{l}\text { Nombre de plantes } \\
\text { RC1 atteignant le } \\
\text { stade floraison }\end{array}$ \\
\hline F1 ( $L$ sativa $\times$ IVT 1398$)$ & 440 & 24 & $1(0)$ & 1 \\
\hline $\mathrm{Fl}($ L. sativa $\times \operatorname{LS} 231)$ & 210 & 11 & $10 \quad(5)$ & 6 \\
\hline F1 (L. sativa $\times$ LS 238) & 257 & 25 & 21 & 12 \\
\hline $\mathrm{F} 1$ (L. sativa $\times \mathrm{LS} 241)$ & 380 & 54 & $40(11)$ & 25 \\
\hline
\end{tabular}

Dans la deuxième expérience, le taux d'obtention des plantes $\mathrm{RCl}$ était variable selon les génotypes femelles $(L$. sativa $\times L$. virosa) : taux très faible pour (L. sativa $\times$ IVT 1398) et taux assez élevé pour $(L$. sativa $\times$ LS 241) (tabl. 5). Quelques capitules des plantes hybrides (L. sativa $\times$ LS 231) et (L. sativa $\times$ LS 238) ont été récoltés à maturité après pollinisation par $L$. sativa; le taux de production des graines $\mathrm{RCl}$ capables de germer était alors très faible avec 2 graines pour 84 capitules et 1 graine pour 147 capitules respectivement. Par contre l'hybride (L. sativa $\times$ IVT 1398) a produit 1 graine mûre pour 33 capitules pollinisés par $L$. sativa contre 1 plante issue de culture in vitro pour 440 capitules pollinisés par $L$. sativa. L'observation des taux de production des plantes $\mathrm{RCl}$ selon le parent mâle $L$. sativa utilisé ne montre pas de nettes différences : 7 à 11 plantes, 2 à 10 plantes, 5 à, 17 plantes et 7 à 10 plantes pour 100 capitules pollinisés respectivement par Girelle, Mélina, Columbus et Ravel.

\section{Etude des plantes obtenues in vitro}

Les plantes hybrides F1 (L. sativa $\times L$. saligna) présentaient un phénotype intermédiaire entre ceux des parents ; quelques plantes contrôlées à l'I.N.R.A., Versailles (L. Roux, comm. pers.) ont donné un diagramme d'électrofocalisation des estérases intermédiaire entre ceux des parents. Il faut noter que parmi les 93 embryons développés, seulement 2 résultaient d'une autofécondation du parent femelle $L$. sativa, VHD dont la stérilité mâle n'est pas complète.

Dans la première expérience, grâce à la multiplication végétative, des plantes, dont certaines étaient issues d'un même embryon, ont pu être étudiées dans différentes conditions (milieu de culture, époque de croissance) (tabl. 6). Parmi les plantes sorties de culture in vitro en automne (cultures $\mathrm{A}, \mathrm{B}, \mathrm{C}, \mathrm{D}$ ), une forte proportion $(108 / 163)$ n'a pas fleuri soit par suite d'une mort à un stade jeune due à un accident de culture ou à une nécrose du système racinaire ou du collet, soit par suite d'une anomalie de croissance (plante albinos ou filiforme, flétrissement des hampes florales). A l'opposé, les quelques plantes sorties de culture in vitro fin décembre (culture E) et placées en serre à la mi-janvier, en jours croissants, se sont en général bien développées puisque 17 plantes sur les 20 ont fleuri. Sur les 60 plantes présentant une floraison, 43 n'ont produit aucune graine après autofécondation naturelle (tabl. 6). Sur les 17 plantes ayant produit des graines

TABLEAU 6

Croissance et fertilité des plantes hybrides Fl (L. sativa $\times \mathrm{L}$. saligna) issues de culture in vitro d'embryons. Growth and fertility of $F I$ (L. sativa $\times \mathrm{L}$. saligna) from immature embryos cultured in vitro.

\begin{tabular}{|c|c|c|c|c|c|c|}
\hline $\begin{array}{l}\text { Cultures : } \\
\text { Dates de repiquage en terre. } \\
\text { Conditions de culture }\end{array}$ & $\begin{array}{c}\text { A } \\
\text { 1 er octobre } \\
\text { Bac sable } \\
\text { hydroponique }\end{array}$ & $\begin{array}{l}\text { B } \\
8 \text { octobre } \\
\text { Mélange tourbe- } \\
\text { sable en pots }\end{array}$ & $\begin{array}{c}\text { C } \\
15 \text { oct. et } 16 \text { nov. } \\
\text { Sol en serre } \\
\text { peu chauffée } \\
\text { Transfert en bac } \\
\text { hydroponique en } \\
\text { février }\end{array}$ & $\begin{array}{l}\mathrm{D} \\
5 \text { et } 14 \text { déc. } \\
\text { Tourbe en pots }\end{array}$ & $\begin{array}{c}\mathrm{E} \\
27 \text { décembre } \\
\text { Mélange tourbe- } \\
\text { argile expansée } \\
\text { en pots }\end{array}$ & Total \\
\hline Plantes repiquées & 37 & 31 & 46 & 49 & 20 & 183 \\
\hline $\begin{array}{l}\text { Plantes mortes par accident } \\
\text { (Botrytis cinerea ou gel) }\end{array}$ & 4 & 6 & 1 & 1 & 0 & 12 \\
\hline $\begin{array}{l}\text { Plantes n'ayant pas fleuri } \\
\text { - nécroses des racines ou du collet } \\
\text { - anomalies à la montaison }\end{array}$ & $\begin{array}{l}10 \\
13\end{array}$ & $\begin{array}{l}9 \\
0\end{array}$ & $\begin{array}{r}38 \\
3\end{array}$ & $\begin{array}{r}26 \\
9\end{array}$ & $\begin{array}{l}0 \\
3\end{array}$ & $\begin{array}{l}83 \\
28\end{array}$ \\
\hline $\begin{array}{l}\text { Plantes ayant fleuri } \\
\text { - stérilité en autofécondation } \\
\text { - fertilité partielle en autofé- } \\
\text { condation }\end{array}$ & $\begin{array}{l}10 \\
0\end{array}$ & $\begin{array}{l}14 \\
2\end{array}$ & $\begin{array}{l}1 \\
3\end{array}$ & 13 & $\begin{array}{r}5 \\
12\end{array}$ & $\begin{array}{l}43 \\
17\end{array}$ \\
\hline
\end{tabular}


en autofécondation, 15 ont fleuri de mars à juin. $\mathrm{Au}$ total près de 2000 graines $F 2$ ont été récoltées, dont plus de 300 graines sur une plante $(A 6614 \times$ CR 16) traitée à la colchicine, la production par plante variant de 1 à 800 graines. Les 17 plantes autofertiles correspondaient à 7 embryons hybrides : 1 embryon (A $6614 \times$ CR 16), 3 embryons (A $6614 \times$ CR 17), 3 embryons (VHD $\times$ CR 17). De plus, les 127 capitules F1 ( $L$. sativa $\times$ CR 16$)$ et 675 capitules F1 ( $L$. sativa $\times \mathrm{CR} 17)$ castrés et pollinisés par $L$. sativa entre février et mai ont produit respectivement 80 et 464 graines RC1.

Dans la deuxième expérience, plus de la moitié des plantes $\mathrm{RCl}$ ( $L$. sativa $\times L$. virosa $) \times L$. sativa ont fleuri en hiver en serre (tabl. 5) et quelques plantes étaient autofertiles : 4 plantes descendant de LS 238 et 7 plantes descendant de LS 241.

\section{DISCUSSION}

La culture in vitro d'embryons immatures, utilisée dans plusieurs genres pour obtenir des hybrides interspécifiques, ne semble pas, à notre connaissance, avoir été employée pour réaliser des croisements dans le genre Lactuca. Les résultats présentés ici montrent que cette méthode peut être utilisée avec succès pour intercroiser des espèces de la section Lactuca.

La mise en culture in vitro sur le milieu gélosé TO d'embryons à cotylédons différenciés âgés de 7 à 10 jours a permis d'obtenir, en 2 à 4 semaines, de belles plantes vertes racinées pour les différents génotypes étudiés.

Dans les 2 croisements effectués, $L$. sativa $\times L$. saligna et $(L$. sativa $\times L$. virosa $) \times L$. sativa, nous avons observé des taux de production de plantes hybrides très variables selon les génotypes. Ainsi CR 16 semblait plus difficile à croiser que CR 17 et IVT 1398 donnait de moins bons résultats que LS 241 ou LS 238. Ceci corrobore les résultats de LINDQVIST (1960) sur les différences d'aptitude aux croisements entre provenance de $L$. saligna et ceux de MAXON SMITH (1984) concernant les croisements entre $L$. sativa et $L$. virosa. Précisons que CR 17 est parfois classée comme $L$. quercina (I. CRUTE comm. pers.); les critères de classification de FERAKOVA (1977) que nous avons adoptés ici et les diagrammes d'électrofocalisation des estérases établis par Roux et al. (1985) permettent de la rapprocher de $L$. saligna.

L'hypothèse de non germination du pollen de L. saligna sur le stigmate de L. sativa (LINDQVIST, 1960) peut être éliminée puisque nous avons obtenu des plantes hybrides $\mathrm{F} 1$ (L. sativa $\times$ L. saligna). La possibilité de réaliser le croisement ( $L$. sativa $\times$ $L$. saligna) permet d'étudier les croisements réciproques et d'introduire des gènes intéressants de $L$. saligna dans la laitue cultivée en gardant le cytoplasme de L. sativa.

L'étude des hybrides ( $L$. sativa $\times$ L. saligna) permet de dégager deux points intéressants. Tout d'abord, il semble possible d'obtenir des plantes $F_{1}$ autofertiles puisque nous avons récolté plus de 300 graines $\mathrm{F}_{2}(L$. sativa $\times \mathrm{CR} 16)$ et plus de 1500 graines $\mathrm{F}_{2}$ (L. sativa $\times \mathrm{CR} 17$ ). D'autre part, les conditions culturales se sont révélées avoir une plus forte influence sur la croissance et la fécondité des plantes hybrides que pour des plantes de L. sativa. En effet, nous n'avons récolté des descendances que sur les plantes cultivées dans de bonnes conditions (jours croissants, forte intensité lumineuse, substrat drainant). Certains de nos hybrides semblent beaucoup plus fertiles que ceux décrits dans la littérature. Nous avons entrepris de contrôler si cette meilleure fertilité des hybrides est due au fait qu'ils possèdent le cytoplasme de $L$. sativa ou à l'origine de $L$. saligna utilisée.

Hormis les travaux de MAXON SMITH (1984), l'obtention de descendance directe de l'hybride ( $L$. sativa $\times L$. virosa) n'a jamais été réalisée auparavant ; les hybrides mouraient au stade rosette, ou leur stérilité était totale. L'obtention de RC après traitement à la colchicine (MAXON SMITH, 1984 ; résultats I.N.R.A. non publiés) est possible mais nécessite de très nombreux recroisements pour revenir à des plantes diploïdes intéressantes. $\mathrm{La}$ culture in vitro d'embryons pourrait donc permettre un transfert direct de gènes de $L$. virosa à $L$. sativa sans utiliser d'espèce-pont, ni doubler les chromosomes à la colchicine. Cette technique vient d'ailleurs d'être appliquée avec succès à l'obtention de $\mathrm{RC}_{1}$ (IVT $280 \times$ L. sativa) $\times$ L. sativa alors que l'exploitation de cette provenance de $L$. virosa, IVT 280, pour améliorer la laitue avait nécessité auparavant l'utilisation d'une espèce-pont (EENINK et al., 1982). Précisons que les embryons mis en culture sont bien formés mais toujours plus petits que les embryons de $L$. sativa de même âge.

L'étude des descendances de LS 238 et LS 241 est en cours ; les premiers tests de résistance au mildiou ont montré que nous avons gardé des gènes intéressants de $L$. virosa alors que certaines plantes F2 de $\mathrm{RC} 1$ ou $\mathrm{RC} 2$ ont déjà des phénotypes assez proches de L. sativa.

En conclusion, la culture in vitro d'embryons immatures semble une technique intéressante pour faciliter la réalisation de croisements interspécifiques dans le genre Lactuca, même si son efficacité varie selon les origines des plantes à l'intérieur des espèces. Les travaux présentés ici montrent son intérêt pour produire des hybrides $(L$. sativa $\times$ L. saligna) et pour obtenir des descendances des hybrides F1 ( $L$. sativa $\times$ L. virosa).

Reçu le 11 juin 1986 Accepté le 10 février 1987.

\section{REMERCIEMENTS}

Nous remercions Claire DORE pour son accueil dans son labora toire et Florence CHARLOT pour son aide technique en culture in vitro ainsi que Christiane LESAINT pour ses conseils culturaux et son accueil dans la serre de Physiologie végétale de Versailles. 


\section{RÉFÉRENCES BIBLIOGRAPHIQUES}

Bannerot H., 1980. Screening wild lettuce for Bremia resistance. In Proc. Eucarpia Meeting on Leafy Vegetables, Littlehampton, 11-14 March 1980. Ed. J. W. Maxon Smith \& F. A. Langton, 104-106.

Bourgin J. P., Nitsch J. P., 1967. Obtention de Nicotiana haploides à partir d'étamines cultivées in vitro. Ann. Physiol. vég., 4, 377 382 .

Eenink A. H., Groenwold R., Dieleman F. L., 1982. Resistance of lettuce (Lactuca) to the leaf aphid Nasonovia ribis nigri. I. Transfer of resistance from $L$. virosa to $L$. sativa by interspecific crosses and selection of resistant breeding lines. Euphytica, 31, 291-299.

Ferakova V., 1976. Lactuca L. In Flora Europaea, 4, Cambridge Univ. Press. Eds. T. G. Tutin et al., 328-331.

Ferakova V., 1977. The genus Lactuca L. in Europe. Ed. Univerzita Komenskeho $\vee$ Bratislave, 122 p.

Gamborg O. L., Miller R. A., Ojima K., 1968. Nutrient requirements of suspension cultures of soybean root cells. Exp. Cell Research, 50, 151-158.

Heller R., 1953. Recherches sur la nutrition minérale des tissus végétaux cultivés in vitro. Ann. Sc. Nat. Bot. Biol. Vég., 14, 1-223.

Lindqvist K., 1960. Cytogenetic studies in the Serriola group of Lactuca. Hereditas, 46, 75-151.

Maxon Smith J. W., 1984. Interspecific hybridisation in Lactuca with particular reference to $L$. sativa $L$. $\times L$. virosa $\mathrm{L}$. In Coll. Eucarpia sur les légumes à feuilles, Versailles, 28 février - 2 mars 1984. Eds. H. Bannerot \& C. Meheut, 21-34.

Monnier M., 1973. Croissance et développement des embryons globulaires de Capsella bursa-pastoris cultivés in vitro dans un milieu à base d'une nouvelle solution minérale. Soc. bot. Fr., Mémoires 1973, Coll. Morphologie, 179-194.

Morel G., Wetmore R. H., 1951. Tissue culture of monocotyledons. Am. J. Bot., 38, 138-140.

Murashige T., Skoog F., 1962. A revised medium for rapid growth and bioassays with tobacco tissue culture. Phys. Plantarum, 15 , 473-497.
Netzer D., Globerson D., Sacks J., 1976. Lactuca saligna L., a new source of resistance to downy mildew (Bremia lactucae Reg.). HortScience, 11, 612-613

Netzer D., Globerson D., Weintal Ch., Elyassi R., 1985. Sources and inheritance of resistance to stemphylium leaf spot of lettuce. Euphytica, 34, 393-396.

Nitsch J. P., Nitsch C., 1969. Haploid plants from pollen grain Science, $163,85-87$.

Nordwood J. M., Johnson A. G., Crute I. R., 1980. The utilisation of novel sources of resistance to Bremia lactucae from wild Lactuca species. In Proc. Eucarpia Meeting of leafy vegetables, Littlehampton, 11-14 March 1980. Eds. J. W. Maxon Smith \& F. A. Langton, 97-103.

Provvidenti R., Robinson R. W., Shail J. W., 1980. A source of resistance to a strain of cucumber mosaic virus in Lactuca saligna L. HortScience, 15, 528-529.

Roux L., Chengjiu Z., Roux Y., 1985. Caractérisation de Lactuca sativa $\mathrm{L}$. et des espèces apparentées par électrofocalisation des estérases. Agronomie, 5, 915-921.

Ryder E. J., 1963. An epistatically controlled pollen sterile in lettuce (Lactuca sativa L.). Proc. Am. Soc. Hortic. Sci., 83, 583-589.

Ryder E. J., 1971. Genetic studies in lettuce (Lactuca sativa L.). J. Amer. Soc. Hortic. Sci., 96, 826-828.

Ryder E. J., Whitaker T. W., 1976. Lettuce. In N. W. Simmonds, Evolution of crop plants., 39-41.

Thompson R. C., Ryder E. J., 1961. Description and pedigrees of nine varieties of lettuce. USDA, Tech. Bull., n ${ }^{\circ} 1244$, ARS, $19 \mathrm{p}$.

Thompson R. C., Whitaker T. W., Kosar W. F., 1941. Interspecific genetic relationship in Lactuca. J. of Agric. Res., 63, 91-107.

Whitaker T. W., Kishaba A. N., Toba H. H., 1974. Host parasite interrelations of Lactuca saligna L. and the cabbage looper, Trichoplusia ni (Hubner). J. Amer. Soc. Hortic. Sci., 99, 74-78. 